\title{
Design rules to fully benefit from bifaciality in two-terminal perovskite/silicon tandem solar cells
}

Olivier Dupré ${ }^{*}$, Arttu Tuomiranta ${ }^{2}$, Quentin Jeangros ${ }^{1}$, Mathieu Boccard ${ }^{1}$, Pierre-Jean Alet $^{2}$, Christophe Ballif ${ }^{1,2}$

${ }^{1}$ École Polytechnique Fédérale de Lausanne (EPFL), Institute of Microengineering (IMT), Photovoltaics and Thin Film Electronics Laboratory, Rue de la Maladière 71b, CH-2002 Neuchâtel, Switzerland

${ }^{2}$ Centre Suisse d'Electronique et de Microtechnique SA (CSEM), Rue Jaquet-Droz 1, 2002 Neuchâtel

\section{"Corresponding author: olivier.dupre@protonmail.com}

\begin{abstract}
The photovoltaics industry is adopting bifacial systems which offer improved energy harvesting compared to monofacial ones. This stems from the collection of light reflected by the surroundings on the rear side of the modules, leading to system-level gains typically ranging from 5 to $25 \%$ rel. The question arises, however, whether this bifacial gain also applies to two-terminal (2T) tandem solar cells, since the series-connected sub-cells must generate equivalent currents to achieve an optimal performance. Using comprehensive simulations based on realistic device characteristics and typical meteorological data at different locations, we demonstrate that $2 \mathrm{~T}$ tandem solar cells can indeed benefit from bifaciality provided that their design is tailored to this configuration. The top cell needs to absorb significantly more light than when designed for monofacial operation. In the geographical locations and system configurations simulated here, a broad performance optimum is found at a mismatch value of $6 \mathrm{~mA} \mathrm{~cm}{ }^{-2}$ under front illumination, corresponding to a top cell generating $\sim 23 \mathrm{~mA} \mathrm{~cm}^{-2}$ compared to $\sim 17 \mathrm{~mA} \mathrm{~cm}^{-2}$ in the bottom one. With such specific design, bifacial tandems can yield up to 1.2 times the energy output of bifacial single-junction devices across a wide range of locations.
\end{abstract}

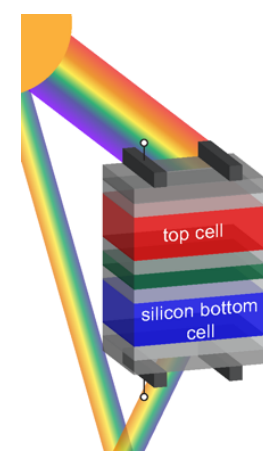

\section{INTRODUCTION}

Two-terminal (2T) perovskite/silicon (Si) tandem devices are a promising upgrade to today's industry backbone, crystalline $\mathrm{Si}$ (c-Si) singlejunction (SJ) solar cells. Indeed, the combination of these two technologies has the potential to yield efficiencies above $30 \%$ [1], about $20 \%$ rel more than industrial c-Si SJs, whose efficiencies are expected to plateau around $25 \%$. In parallel

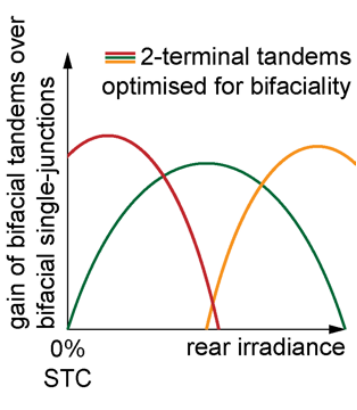

to these developments, utility-scale PV installations are gradually switching to bifacial cSi SJ solar modules. Harvesting light not only from the front side of the modules but also from their rear promises gains in system-level energy production between $5-15 \%$ rel for large $\mathrm{PV}$ systems and up to $25 \%$ rel for small systems optimised for bifaciality [2]-[5]. However, these two technological shifts, tandems and bifacial 
SJs, are occurring independently from each other.

In bifacial tandems, the additional light that will reach the rear side will be absorbed solely in the bottom cell. Bifaciality does not necessarily translate into a performance gain in tandems since the sub-cells are serially connected and performance depends strongly on current matching between the two sub-cells [6], [7]. Whether $2 \mathrm{~T}$ tandems will benefit as much as SJs from a bifacial configuration and maintain their theoretical efficiency advantage in field conditions remains an open question. The answer will determine which technology, monofacial or bifacial devices, SJs or tandems, will be preferred depending on location and system requirements. This answer is not trivial since the fraction of rear irradiance varies significantly depending on location, spectrum, temperature, ground, and system configuration (module height, tilt angle, orientation, row spacing, etc.).

Earlier works have shown that $2 \mathrm{~T}$ tandems could benefit from a bifacial configuration by changing the spectral response of the absorber of the top cell [8]-[10]. The tandem must be bottom-celllimited in the absence of any rear illumination, which can be achieved by increasing the thickness of the top cell absorber and/or reducing its bandgap. So far, bifacial tandem efficiencies have been mostly simulated assuming a constant fraction of light reaching the rear of the device. However, in the field, a 2T device will experience a wide range of rear-to-front irradiance ratios depending on the sun's position, the system configuration, etc., meaning that it will operate at different current mismatch levels (see e.g. [11]).

Yet, important operating parameters such as incident spectrum and module temperature have not been accounted for so far. These effects may combine, sometimes in subtle ways, to influence energy yields, especially for tandems [6]. The fraction of rear irradiance depends notably on the position of the sun, which is correlated with module temperature and incident spectra. For example, at sunrise, the rear irradiance ratio is usually large, the direct solar beam spectrum red, and the module temperature low. We address these intertwined effects by combining an inhouse effective irradiance algorithm to an electrothermal model to compute the power output at every time step of the year for various locations and ground types. This approach enables a detailed assessment of the performance of bifacial tandems and provides design guidelines.

\section{DEVICE DESCRIPTION}

In the following simulations, we compared two devices that could in the near future compete for shares of the PV market: a high-efficiency industrial c-Si solar cell and a perovskite/c-Si tandem. The latter (Figure 1a) provides a large efficiency gain (estimated to be $+5.7 \%$ abs in this work). For the SJ and the bottom cell of the tandem, the $24 \%$-efficient silicon heterojunction $(\mathrm{SHJ})$ solar cell of Meyer Burger reported in Ref. [12] was chosen. A two-diode model was used to fit its current-voltage (IV) characteristics. For the top cell of the tandem, parameters were extracted from the IV curve of a $23.7 \%$-efficient perovskite SJ solar cell [13]. Cell parameters are given in Table 1 in black italic letters. a)

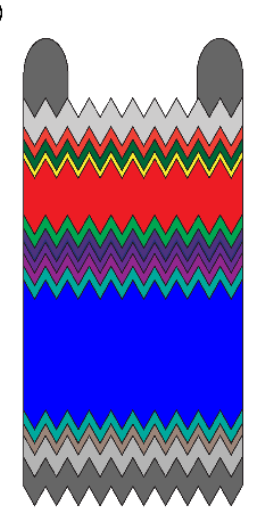

b)

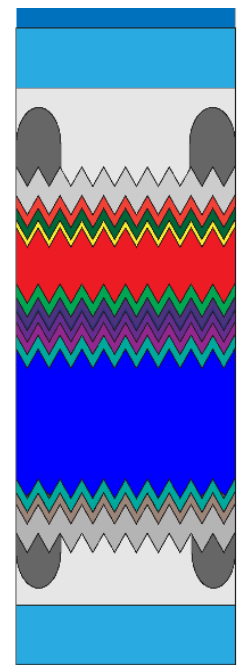

glass ARC (110 nm) glass (2 mm) EVA $(0.45 \mathrm{~mm})$ $\mathrm{Ag}$ IZO $(110 \mathrm{~nm})$ $\mathrm{SnO}_{2}(10 \mathrm{~nm})$ $\mathrm{C}_{\mathrm{BO}}(15 \mathrm{~nm})$ LiF $(1 \mathrm{~nm})$ perovskite (variable) spiro-TTB (12 nm) (nc-Si: $H\left(p^{+}\right) \quad(20 \mathrm{~nm})$ a-Si:H(n) (2nm) a-Si:H(i) $(2 \mathrm{~nm})$ c-Si $(150 \mu \mathrm{m})$ a-Si:H(i) $(2 \mathrm{~nm})$ a-Si:H(p) $(3 \mathrm{~nm})$ ITO $(135 \mathrm{~nm})$ $\mathrm{Ag}(180 \mathrm{~nm})$ EVA $(0.45 \mathrm{~mm})$ glass $(2 \mathrm{~mm})$

Figure 1: Layer stacks simulated with SunSolve: a) monofacial cell configuration and b) bifacial module configuration.

The efficiencies of these monofacial cells were then converted into bifacial module performance using the following assumptions. The cells are 
interconnected using a multiwire approach with 18 wires of $300 \mu \mathrm{m}$ in diameter, which results in a cell-to-module resistance of $0.4 \mathrm{Ohm} \mathrm{cm}{ }^{-2}$. The current densities were simulated with SunSolve [14] assuming $0.45 \mathrm{~mm}$ of EVA and $2 \mathrm{~mm}$ of glass on both sides (the complete layer stack is shown in Figure 1b). The glass on the front side features an antireflective coating. The thickness and the composition of the perovskite top cell was varied to tune the current mismatch between the subcells under front illumination without affecting its other modelling parameters. The refractive index and extinction coefficients $(n, k)$ used as inputs for SunSolve were extracted from in-house spectroscopic ellipsometry measurements of the different layers [15], [16], except for the low bandgap $\left(\mathrm{FASnl}_{3}\right)_{0.60}\left(\mathrm{MAPb}_{3}\right)_{0.40}$ perovskite composition, which were obtained from [17].

\begin{tabular}{|c|c|c|c|c|}
\hline \multicolumn{5}{|c|}{$\begin{array}{c}\text { Device IV parameters } \\
\text { Monofacial configuration at the cell level } \\
\text { Bifacial configuration at the module level }\end{array}$} \\
\hline & $\begin{array}{c}\eta \\
(\%) \\
\end{array}$ & $\begin{array}{c}J_{\mathrm{sc}} \\
\left.(\mathrm{mA} \mathrm{cm})^{-2}\right)\end{array}$ & $\begin{array}{c}V_{\mathrm{oc}} \\
(\mathrm{mV})\end{array}$ & $\begin{array}{l}F F \\
(\%)\end{array}$ \\
\hline SJ HJT & $\begin{array}{l}24.0 \\
20.9 \\
\end{array}$ & $\begin{array}{l}39.3 \\
37.1 \\
\end{array}$ & $\begin{array}{l}739 \\
736 \\
\end{array}$ & $\begin{array}{l}82.7 \\
80.9 \\
\end{array}$ \\
\hline $\begin{array}{c}2 \mathrm{~T} \\
\text { tandem }\end{array}$ & $\begin{array}{l}29.7 \\
26.6\end{array}$ & $\begin{array}{l}19.6 \\
18.5\end{array}$ & $\begin{array}{l}1870 \\
1866\end{array}$ & $\begin{array}{l}81.0 \\
81.0\end{array}$ \\
\hline \multicolumn{5}{|c|}{ Inputs of 2-diode model } \\
\hline & $\begin{array}{c}I_{01} \\
\left.(\mathrm{~mA} \mathrm{~cm})^{-2}\right)\end{array}$ & $\begin{array}{c}\mathrm{I}_{02} \\
\left.(\mathrm{~mA} \mathrm{~cm})^{-2}\right)\end{array}$ & $\begin{array}{c}R_{s} \\
(\mathrm{Ohm} \\
\left.\mathrm{cm}^{2}\right)\end{array}$ & $\begin{array}{c}R_{s h} \\
(\mathrm{kOhm} \\
\left.\mathrm{cm}^{2}\right)\end{array}$ \\
\hline SJ HJT & $1.510^{-11}$ & & $\begin{array}{l}0.48 \\
0.88\end{array}$ & 10 \\
\hline $\begin{array}{c}2 T \text { top } \\
\text { cell }\end{array}$ & $3.510^{-19}$ & $1.510^{-9}$ & 2.3 & 2 \\
\hline $\begin{array}{l}2 \mathrm{~T} \text { bottom } \\
\text { cell }\end{array}$ & $1.510^{-11}$ & & $\begin{array}{l}0.48 \\
0.88\end{array}$ & 10 \\
\hline
\end{tabular}

Table 1: IV parameters and 2-diode model inputs.

Since the current in a tandem is about half of that in a SJ, the number of fingers was optimized to minimize shading and resistive losses for each configuration (Figure 2). These computations were made using the following parameters: sheet resistances of $100 \mathrm{Ohm} / \mathrm{sq}$ and $130 \mathrm{Ohm} / \mathrm{sq}$ for the front and rear side, respectively, finger line resistance of $0.8 \mathrm{Ohm} \mathrm{cm}^{-1}$, and optical finger width (encapsulated in module) of $33 \mu \mathrm{m}$. An active cell area ratio (total area of the cells over the module area) of $95 \%$ was assumed. The resulting IV parameters for the different bifacial module configurations are listed in Table 1 in bold grey letters.

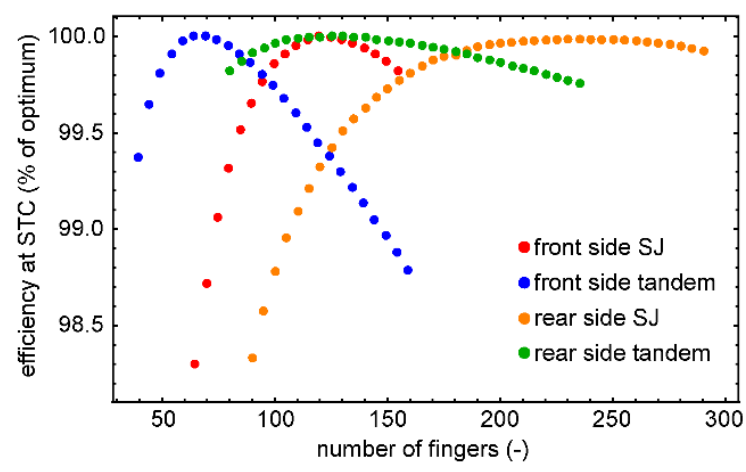

Figure 2: Efficiency versus number of fingers at the front and rear. The optimum results from the trade-off between optical shading and resistive losses caused by metallisation.

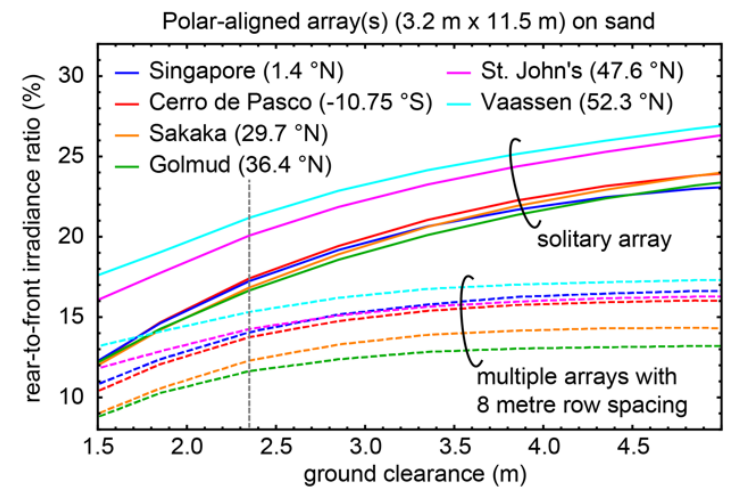

Figure 3: Simulated annual rear-to-front irradiance ratios for a solitary polar-aligned array (continuous lines) and multiple polar-aligned arrays (dashed lines) of $2 \times 12$ modules in portrait configuration in different locations as a function of the array height. These simulations use the average irradiance levels over all of the 1440 cells of the 24 modules. The vertical dashed grey line shows the height value used in this study.

At the system level, the average irradiance received on the rear side varies significantly with the size of the module array, the height of the mounting structure, the row spacing, the tracking system, etc. To illustrate this, Figure 3 shows the simulated annual rear-to-front-illumination ratios of solitary or multiple arrays of $2 \times 12$ modules (in portrait, fixed polar-aligned mounting) in different locations as a function of the array height above the ground, i.e. the ground clearance. For the rest 
of the analysis, a representative value of $2.35 \mathrm{~m}$ between the ground and the array centre was selected. Another critical parameter in a bifacial PV plant is the spacing between the rows of the array (Figure 3 ). The optimal spacing eventually results from a trade-off between bifacial gain and area-dependent system costs. In this work, we restricted the simulations to the solitary array configuration for clarity to highlight differences between bifacial SJs and bifacial tandems. The text below hence discusses a solitary array of $2 x$ 12 modules in portrait configuration on a fixed polar-aligned mounting at a height of $2.35 \mathrm{~m}$. Yet, it is important to keep in mind that the bifacial gain compared to monofacial cells will decrease when inter-row shading is considered (e.g. by $\sim 30 \%$ rel for an $8 \mathrm{~m}$ row spacing, see Figure 3 ). The ground surface type 'sand' used in Figure 3 and in this study refers to the reference spectral albedo assumed when simulating the AM1.5G spectrum: light yellowish brown loamy sand [18].

Simulations shown here are based on average irradiance levels over all of the 1440 cells of the 24 modules. In the field, the effective irradiance will vary between cells as they have distinct view factors to the sky and, for bifacial modules, to (un)shaded parts of the ground. The cell-to-cell current mismatch that will result was neglected here. While some mismatch can be balanced by a gain in FF [19], the mismatch induced by a partial shading of the rear will eventually limit the gain in performance of bifacial modules (SJs and tandems) compared to monofacial ones. The results presented in this manuscript should hence be viewed as an upper bound of the performance that can be achieved in bifacial conditions. Yet, these simulations yield a direct comparison between bifacial SJs and bifacial tandems.

\section{ESTIMATION OF BIFACIAL ENERGY HARVESTING BY 2T TANDEMS}

This section presents a first set of calculations which account only for the bifaciality and the mismatch that it induces between the sub-cells. Thermal and spectral effects, which also affect the mismatch significantly, are therefore neglected in this first approximation.
Nevertheless, such simple calculations, illustrated in Figure 4, enable to estimate how $2 \mathrm{~T}$ tandems may perform in a bifacial configuration. A front irradiance of $1000 \mathrm{~W} \mathrm{~m}^{-2}$ is assumed, with different rear irradiance fractions and a bifaciality of $90 \%$. The AM $1.5 \mathrm{G}$ spectrum is assumed for front irradiance and the device temperature is fixed at $25^{\circ} \mathrm{C}$. Four devices are compared: a SJ, a current-matched $2 \mathrm{~T}$ tandem, and two other $2 \mathrm{~T}$ tandems with $6 \mathrm{~mA} \mathrm{~cm}{ }^{-2}$ and $12 \mathrm{~mA} \mathrm{~cm} \mathrm{~cm}^{-2}$ of mismatch, respectively. Mismatch is defined here as the current photogenerated in the top cell minus the one photogenerated in the bottom cell under STC conditions (1000 W m ${ }^{-2}$ AM1.5G front illumination and no rear illumination). For example, a mismatch of $6 \mathrm{~mA} \mathrm{~cm}{ }^{-2}$ corresponds to $\sim 23 \mathrm{~mA} \mathrm{~cm}^{-2}$ and $17 \mathrm{~mA} \mathrm{~cm}^{-2}$ generated in the top and bottom cell, respectively.
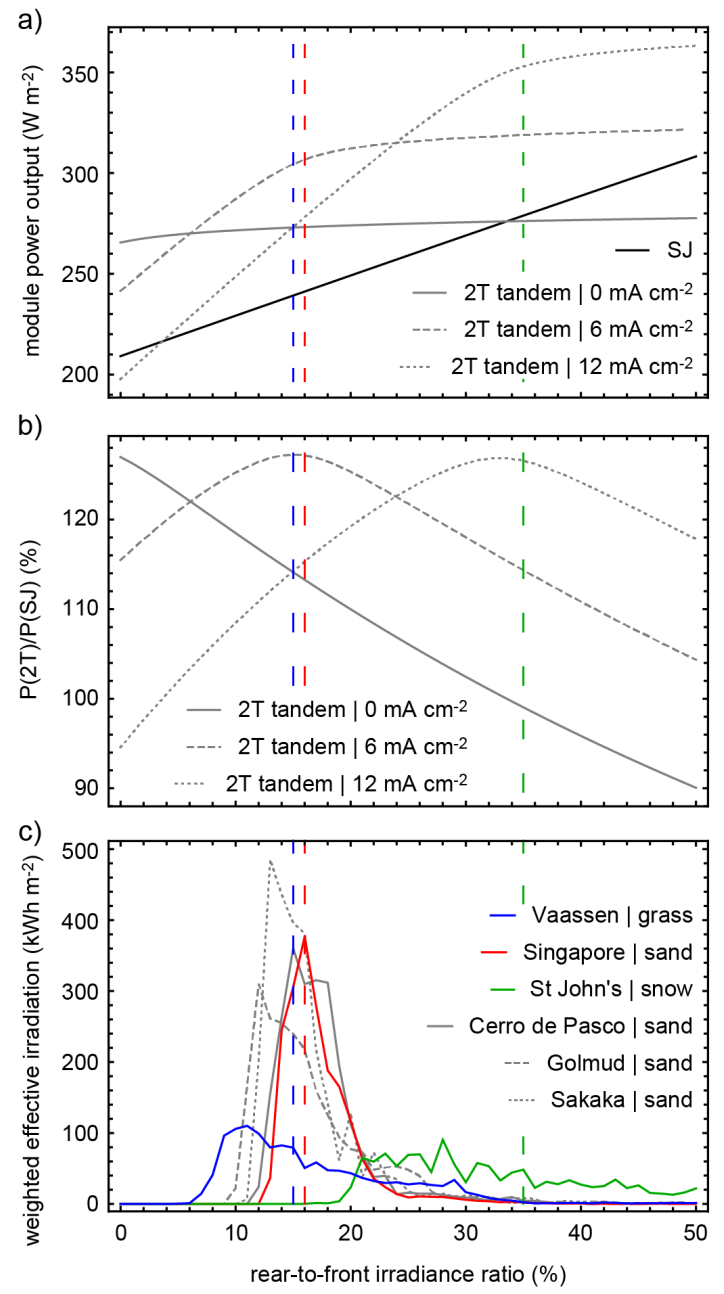

Figure 4: a) module power, b) power ratio 
between tandems and SJ, c) yearly weighted effective irradiation distribution, all as a function of the rear-to-front irradiance ratio. Vertical lines mark median rear-to-front irradiance ratios for a selection of field conditions. The weighted effective irradiation is defined as the radiant exposure of the module surface corrected for the impact of incidence angle on reflection losses. Additionally, the weights are 1 for the front and 0.9 for the rear to account for bifaciality.

Figure 4a shows that the power output of the SJ device increases almost linearly with rear irradiance, the slight sub-linearity being caused by series resistance. On the other hand, the power outputs of the tandem devices increase sharply up to the value of rear irradiance at which their sub-cells become current-matched, after which they slowly saturate (beyond current matching, the power output still slightly increases through an increase in FF [7]). Figure 4b shows the power ratio between the tandems and the SJ. It illustrates two important points: 1) a tandem mismatched under STC (when there is no rear illumination) will outperform an STC-matched tandem on a wide range of rear irradiance values, and 2) a bifacial tandem optimized for STC, i.e. with a mismatch of $0 \mathrm{~mA} \mathrm{~cm}{ }^{-2}$, will output less power than a SJ module at high rear irradiance values (at $>35 \%$ of rear-to-front irradiance in this example). Yearly rear-to-front irradiance ratio distributions of several locations are plotted in Figure 4c. The distributions were calculated using the algorithm discussed in the next section. Median values for most of these locations are in the range of $15 \%$, in most cases with only a few percent of spread, indicating already that a tandem mismatched in favour of its top cell by about $6 \mathrm{~mA} \mathrm{~cm}^{-2}$ would perform well. In St. John's, with a snowy background, a larger mismatch would be necessary to benefit efficiently from a bifacial configuration. Still, tandem devices optimised for these high rear irradiance conditions (e.g. with a mismatch at STC of $\sim 12$ $\mathrm{mA} \mathrm{cm}{ }^{-2}$ ) could outperform a bifacial SJ by up to $23 \%$ rel. This efficiency boost induced by switching from a bifacial $\mathrm{SJ}$ design to a bifacial tandem configuration, even at high rear irradiances, is similar to the gain of $27 \%$ rel obtained in STC when switching from a monofacial SJ module to a monofacial tandem module (see Table 1).

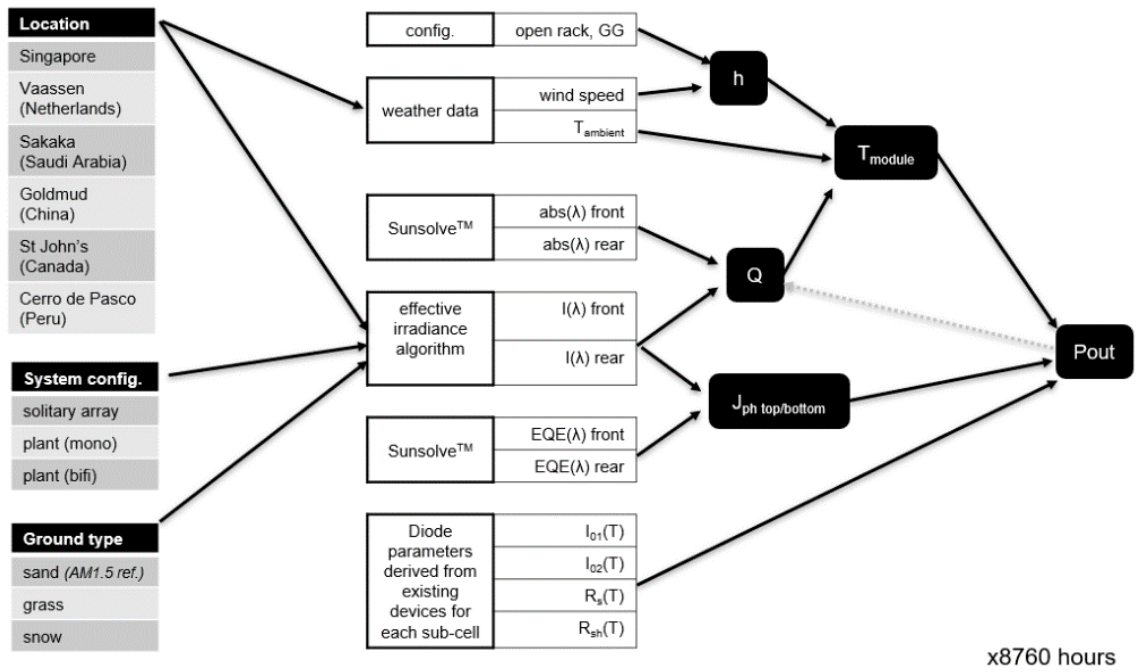

Figure 5: Schematic view illustrating the optical-electrical-thermal modelling framework.

\section{DETAILED BIFACIAL ENERGY YIELDS ALGORITHM}

Although the simple approach described above enables to estimate the potential bifacial gain of $2 \mathrm{~T}$ tandems, it does not account for important operating parameters such as incident spectra and module temperature. The impact of these intertwined mechanisms on performance are solved here using a simulation framework depicted in Figure 5 and discussed in detail in the 
next two sections. In short, the effective irradiance algorithm developed in-house calculates the spectrally and angularly resolved irradiance on the front and rear of a module for various system configurations (including also array size, tracking system, etc.), in different locations and with various ground types. The results of this algorithm are coupled with an electro-thermal model that calculates the module operating temperature from the heat balance and provides the power output at every time step during the year.

\section{Effective irradiance computations}

The number of photons that are absorbed by the solar cells is not only determined by the broadband level of the incident radiant flux but also by the flux incidence angle and spectral distribution. The standard test conditions (STC) fix the three factors at their " 1 sun" values. Under actual operating conditions however, these factors vary with weather and sun position. The time series of incoming photon flux is derived here from publicly available meteorological year datasets [20] using an effective irradiance algorithm. The algorithm is based on view factor estimation and has been designed for bifacial PV arrays operated in complex radiative surroundings such as a tracking system and/or a system of multiple PV arrays. Ray tracing is an alternative to this view factor-based approach but due to its high computational requirements, it is not considered as practical for long-term array performance simulation [21]. First, angularly and spectrally resolved photon fluxes incident on each side of the planes of the arrays and on the system ground surface are estimated by means of an anisotropic sky radiance model adapted from Ref. [22] and a surface reflectance model allowing for different levels of complexity. When estimating the incident fluxes, the algorithm considers array cross-shading and crossblocking as well as array blocking of the sky from the viewpoint of both arrays and ground. As a result, irradiance can be modelled separately for each cell of a considered array. Moreover, array cross-reflection and transmittance can be modelled by the algorithm. Second, the spectral and angular deviations from STC are addressed by estimating the effective irradiance through a correction procedure that converts the irradiance units from $\mathrm{W} \mathrm{m}^{-2}$ to suns, enabling the usage of proportionality when estimating photocurrent based on irradiance. The angular reflection of incident photons is quantified by the model of Ref. [23]. Spectral distributions of beam and sky diffuse irradiance are separately modelled using SMARTS [24], [25] by varying air mass, while keeping the other input parameters at their STC levels. Additionally, the spectral albedo distributions given in the ASTER Spectral Library [18] are used when estimating ground-reflected irradiance. Although spectral albedo is hence assumed as constant, the resulting broadband surface reflectance varies in time due to the temporally variable diffuse fraction of the irradiance incident on the ground. The three ground surface types considered in the study include light yellowish brown loamy sand, grass, and coarse granular snow with respective broadband reflectance levels of $0.33,0.24$, and 0.77 under an AM1.5G illumination [18].

\section{Electro-thermal model}

The heat source (Q) within the module is calculated from the rear and front incident spectra and the spectrally resolved absorptivity simulated with SunSolve from PVlighthouse [14]. In an iterative process, the electrical power output of the module is subtracted from the heat source, the module temperature ( $\left.T_{\text {module }}\right)$ is recalculated and the power output re-evaluated until convergence, as described in [26]:

$T_{\text {module }}=T_{a m b}+\frac{Q}{u} \quad$ with $\quad u=u_{0}+u_{1} v_{w}$

where $T_{a m b}$ is the ambient temperature, $u$ is a global heat transfer coefficient that accounts for all the heat transfer mechanisms and $v_{w}$ is the wind speed. We use standard coefficients suggested by the documentation of PVsyst: $u_{0}=$ $25 \mathrm{~W} \mathrm{~m}^{-2} \mathrm{~K}^{-1}$ and $u_{1}=1.2 \mathrm{~W} \mathrm{~m}^{-2} \mathrm{~K}^{-1} \mathrm{~m}^{-1} \mathrm{~s}$. The wind speed is retrieved from [20] for each location. The photogenerated current in the top and bottom cells are calculated from their EQE simulated with SunSolve and the rear and front 
incident spectra from the effective irradiance algorithm. The module power is then calculated using a two-diode model with the parameters shown in Table 1. The assumed temperature dependences correspond to the scenarios described in Section 2.3.1 of [26]. These assumptions result in temperature coefficients of $-0.34 \% \mathrm{~K}^{-1}$ and $-0.23 \% \mathrm{~K}^{-1}$ for the SJ and the tandem devices, respectively. While temperature coefficients of future industrial perovskite cells remain to be measured, it is observed that temperature coefficients generally improve with device efficiency (for efficient devices not severely limited by series or shunt resistances).

\section{BIFACIAL TANDEM ENERGY YIELDS}

Figure 6 shows the ratio between the annual energy produced by the tandems and that produced by the SJ device in different locations corresponding to different operating conditions. In STC, when only front illumination is applied, the tandem should ideally be mismatched by 1 $\mathrm{mA} \mathrm{cm}{ }^{-2}$ to maximize its output, thus producing $127 \%$ of the power of the SJ. This necessary mismatch is a consequence of the difference in FF between the sub-cells [7]. In most of the operating scenarios simulated in this work (solitary array of $2 \times 12$ modules in portrait on a fixed polar-aligned mounting), it appears that a bifacial tandem should ideally be mismatched by about $6 \mathrm{~mA} \mathrm{~cm}^{-2}$ in favour of the top cell. Variations of the system configuration (e.g. height of the modules above the ground or row spacing) can modify the average rear-to-front-irradiance ratio (see Figure 3 ) and thus the target mismatch value. The example of a high latitude location, St. John's, with a snowy background results in a larger median rear-to-front-irradiance ratio and the optimal mismatch value calculated is around $13 \mathrm{~mA} \mathrm{~cm}^{-2}$. Overall, the results highlight that although the advantage of a tandem device over a SJ varies with the locations and operating conditions, there is an opportunity to achieve a performance boost of $\sim 20 \%$ rel by switching from bifacial SJ to bifacial tandem devices, provided that the latter are adequately current mismatched at STC.

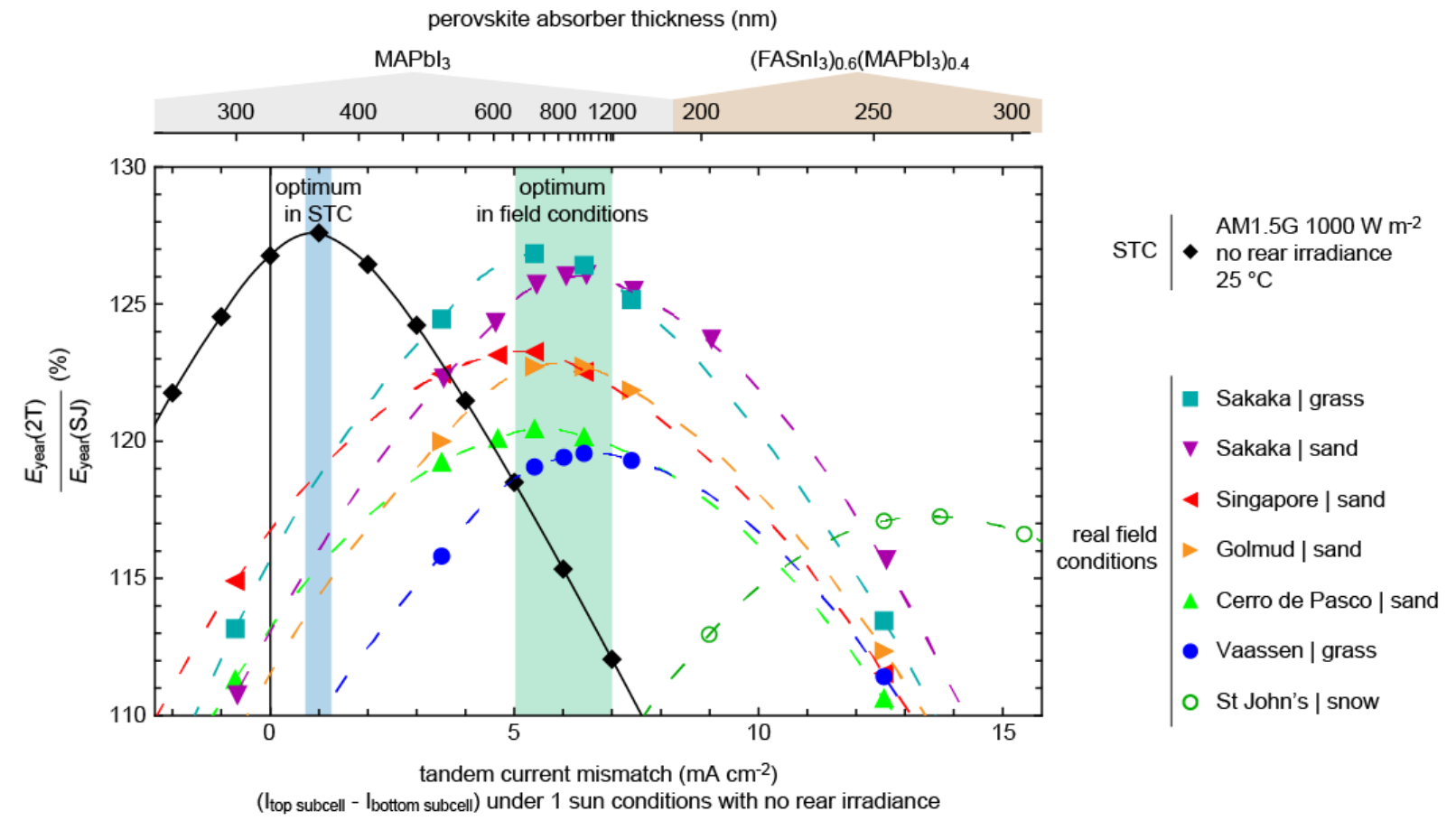

Figure 6: Ratio between the annual energy production of $2 T$ tandems with different sub-cell mismatch and that of a SJ in different locations/operating conditions. The tandem current mismatch values stem here from 
variations in thickness and/or composition of the perovskite absorber. The optimal mismatch (under 1 sun conditions and no rear irradiance) is highlighted in blue for STC and in green for actual field conditions.

Operation conditions vary significantly depending on location. This is illustrated in Figure 7 for the case of tandems operating in Vaassen (Netherlands) and Singapore. It is noteworthy that STC do not occur in either location. In Singapore, the median temperature is around $45{ }^{\circ} \mathrm{C}$ and thus the temperature coefficients play a crucial role. In Vaassen, the median temperature is closer to $25^{\circ} \mathrm{C}$ but the median irradiance is significantly lower than the $1000 \mathrm{~W} \mathrm{~m}^{-2}$ of STC, meaning that low irradiance performance will play a large role. Additionally, the illumination spectra can be very different between locations (depending on latitude and local climate [6]). The impact of these effects on the performance of bifacial tandems will be discussed in the next paragraphs.

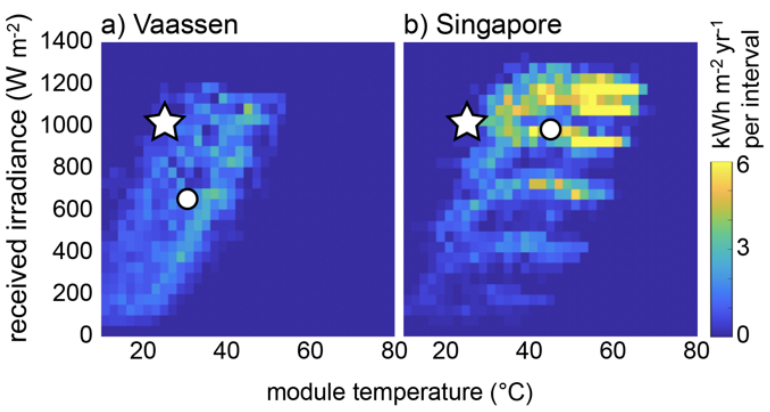

Figure 7: Simulations of distribution of annual energy production in bins of module temperature and received irradiance for tandem devices in Vaassen (NL) (a) and Singapore (b). The weighted median operating conditions are depicted by a white circle and the STC by a white star.

\section{Impact of low irradiance conditions}

Figure 8 illustrates the variation in efficiency of the SJ and tandems (at $25{ }^{\circ} \mathrm{C}$ ) as a function of irradiance. In low illumination conditions, the tandem device (red dots) experiences a large drop in its performance relative to its 1 sun level. It should be noted that this effect does not stem primarily from a low shunt resistance (see blue dots denoting a tandem with a $R_{s h} 10$ times larger) but from low series resistance losses in 1 sun conditions compared to the SJ. Indeed, a tandem with a $R_{s}$ twice as large (green dots) would be impacted by a low irradiance similarly to the SJ device. Using the energy-weighted irradiance distribution in Vaassen (see Figure 8b), one can estimate the low irradiance loss contribution to the performance ratio: $1.1 \%$ for the SJ and $2.6 \%$ for the tandem. This low irradiance loss accounts for a third of the difference between the relative performances in Vaassen as compared to STC in the complete simulations of Figure 6.

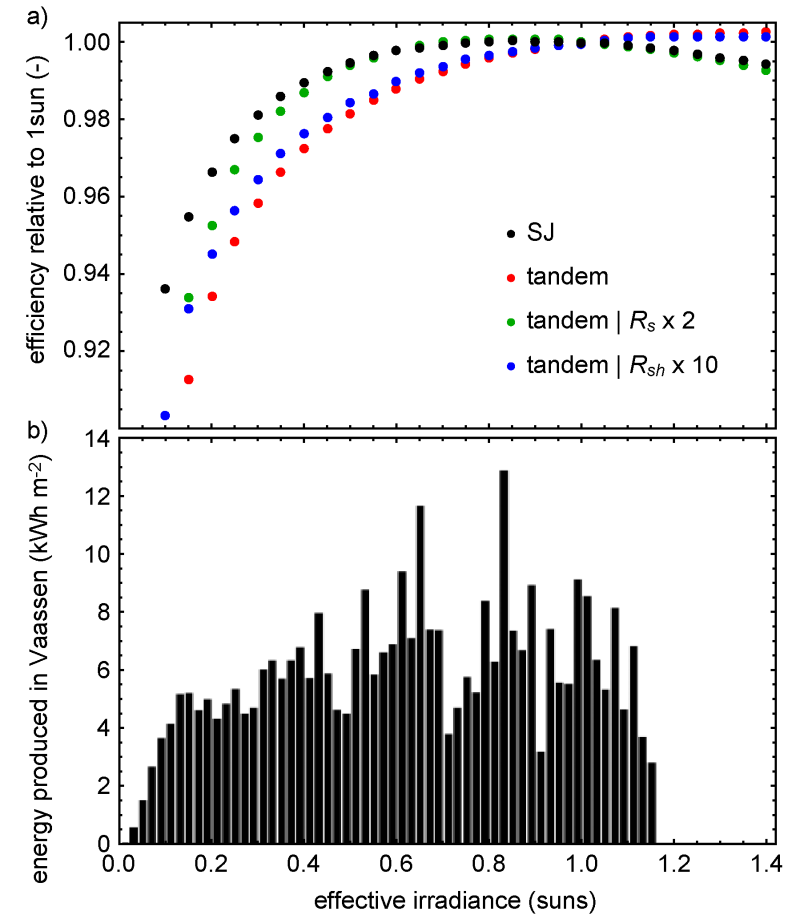

Figure 8: a) Impact of $R_{s}$ and $R_{s h}$ on the relative performance in low and high irradiance conditions; b) Distribution of annual energy produced over effective irradiance bins in Vaassen (NL).

\section{Impact of current mismatch}

The spectrum of the incident radiation is particularly important for the performance of $2 \mathrm{~T}$ tandem devices since they require a certain current balance between the sub-cells to perform optimally. In the field, the spectral pattern varies as a function of both time of day and year due to its dependence on the optical air mass. In addition to this systematic variability caused by the sun position, the weather, i.e. changes in atmospheric composition (clouds, aerosols, etc.), naturally influence the spectrum. The level and the pattern of the variability in spectral irradiance hence largely depend on location. It was 
previously shown that spectrally induced current mismatch did not dramatically reduce the energy yield of $2 \mathrm{~T}$ tandems provided that they were appropriately designed for their operating conditions [6]. Overall, whatever its mismatch under STC, a 2T tandem operates efficiently around its current matching condition. For example, the distributions of average photon energies (APE) and rear-to-front irradiance ratios are particularly narrow in Sakaka (Saudi Arabia, Figure 9), which explains the excellent performance of the tandem in this location (Figure 6). On the other hand, the spectral distribution in Vaassen is larger (Figure 9), meaning that the mismatch loss caused by spectral variations is inevitably important (Figure 6).

In addition, the distribution of rear-to-front irradiance ratio is also significantly spread in Vaassen (see Figure 4c), which adds to the mismatch loss caused by spectral variations. However, as illustrated in the inset of Figure 9, it appears that there is a fortunate correlation between APE and rear-to-front irradiance ratio. When the rear-to-front irradiance ratio is high (usually in the morning and evening), the APE is large (i.e. blue-rich spectrum). This aspect results from two competing effects: as the sun sets, the air mass increases and the direct spectrum is red-shifted. But on the other hand, the fraction of diffuse light (which is blue rich) increases. The latter effect dominates and leads to the blue shift of the effective irradiance on the front of the module, which happens together with an increase of the rear-to-front irradiance ratio. Both mechanisms somewhat compensate the mismatch that they would cause individually.

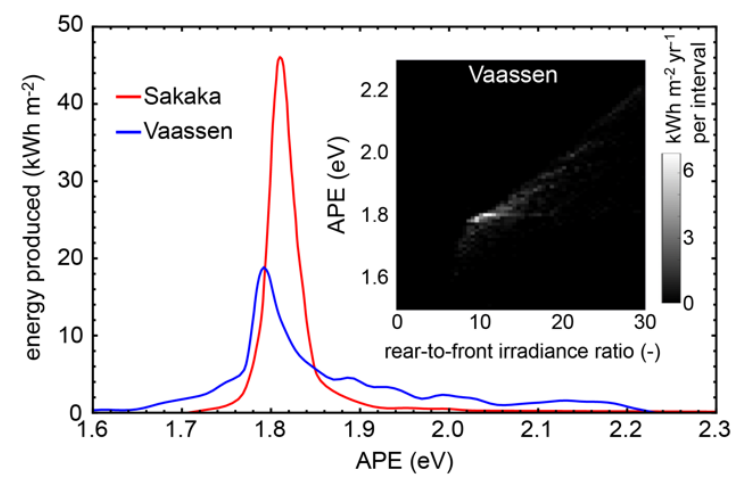

Figure 9: Energy output distribution in Vaassen (NL) and Sakaka (SA) as a function of the average photon energy (APE) of the spectrum received by the front side of the module (using photons in the $300-1100 \mathrm{~nm}$ range). Inset: energy produced in Vaassen versus APE of the spectrum received by the front side of the module and the rear-to-front irradiance ratio.

\section{Impact of temperature}

In the simulations, the temperature coefficients for SJs and tandems are -0.34 and $-0.23 \% \mathrm{~K}^{-1}$, respectively. This difference causes variations of performance ratios that are proportional to the gap between the median operating temperature and 25 ${ }^{\circ} \mathrm{C}$. For example, in Singapore, the median operating temperature is about $45^{\circ} \mathrm{C}$, which results in a temperature-induced difference of performance ratio of about $2.2 \%$ between the SJ and the tandem.

\section{IMPLICATIONS ON TOP CELL DESIGN}

The results of the comprehensive simulation framework used in this work show that $2 \mathrm{~T}$ tandem devices can efficiently benefit from operation in bifacial configuration. A mismatch of $\sim 6 \mathrm{~mA} \mathrm{~cm}{ }^{-2}$ under front illumination (bottom cell-limited condition) is ideal for a wide range of relevant bifacial operating conditions. This corresponds to a semi-transparent top cell generating $\sim 23 \mathrm{~mA} \mathrm{~cm}^{-2}$, which could be achieved by an $800 \mathrm{~nm}$-thick absorber of $\mathrm{MAPbl}_{3}\left(\mathrm{E}_{\mathrm{g}} \approx 1.55 \mathrm{eV}\right)$ or a $<200 \mathrm{~nm}$ thick layer of $\left(\mathrm{FASnl}_{3}\right)_{0.6}\left(\mathrm{MAPbl}_{3}\right)_{0.4}\left(\mathrm{E}_{\mathrm{g}} \approx 1.2 \mathrm{eV}\right)$ [15]-[17]. In the end, the top cell that provides the maximum voltage at the required thickness should be selected to achieve the highest tandem performance. Bifacial tandems should hence feature a perovskite absorber with a lower bandgap compared to standard monofacial tandem devices, where $1.7-1.8 \mathrm{eV}$ is typically mentioned for optimum performance [16], [27]. Advantageously, some of these lower bandgap perovskites optimal for bifaciality exhibit a lower voltage deficit to the bandgap as they are not prone to the light-induced phase segregation occurring in the case of mixediodide/bromide compositions with bandgaps suited for monofacial tandems [28], [29].

While perovskite/silicon devices were used as an example throughout this study, the results obtained here can be generalized to various $2 \mathrm{~T}$ tandem devices. It is worth mentioning that, because of their 
bandgaps, CdTe or GaAs would be particularly wellsuited for the top cell of c-Si-based bifacial tandem devices [10], provided that these cells could be deposited directly on $\mathrm{C}-\mathrm{Si}$ without losing in performance and/or deteriorating the bottom cell.

\section{CONCLUSIONS}

An effective irradiance algorithm was combined with electro-thermal modelling to compare the performance of bifacial SJs and bifacial tandem devices in various meteorological and ground albedo conditions. The combined effects of module temperature, solar spectrum and rear-to-front irradiance ratio are all accounted for in our simulation framework. The results highlight the need to adapt the design of tandem solar cells to a specific operation condition for them to fully benefit from a bifacial configuration. In other words, it means that the tandem device needs to be limited in current by the bottom cell in the absence of rear illumination. The optimal mismatch depends on location, system mounting, ground albedo, etc. However, in the cases investigated here, a solitary array of $2 \times 12$ modules with a fixed polar-aligned mounting, bifacial tandems with $6 \mathrm{~mA} \mathrm{~cm}{ }^{-2}$ of mismatch in favour of the top cell are predicted to benefit efficiently from the additional rear irradiance and to outperform their bifacial SJ counterparts by $>20 \%$ rel.

\section{REFERENCES}

[1] J. Werner, B. Niesen, and C. Ballif, "Perovskite/Silicon Tandem Solar Cells: Marriage of Convenience or True Love Story? - An Overview," Adv. Mater. Interfaces, vol. 5, no. 1, p. 1700731, Jan. 2018.

[2] EPRI, "Bifacial Solar Photovoltaic Modules," 2016.

[3] J. S. Stein, D. Riley, M. Lave, C. Hansen, C. Deline, and F. Toor, "Outdoor Field Performance from Bifacial Photovoltaic Modules and Systems," in 2017 IEEE 44th Photovoltaic Specialist Conference (PVSC), 2017, pp. 3184-3189.

[4] C. Reise, "Predicting Yields for Bifacial PV Systems," Fraunhofer ISE, 2018. .

[5] C. Deline, S. A. Peláez, B. Marion, B.
Sekulic, M. Woodhouse, and J. Stein, "Bifacial PV System Performance:

Separating Fact from Fiction," NREL, 2019.

[6] O. Dupré, B. Niesen, S. De Wolf, and C. Ballif, "Field Performance versus Standard Test Condition Efficiency of Tandem Solar Cells and the Singular Case of Perovskites/Silicon Devices," J. Phys. Chem. Lett., vol. 9, no. 2, pp. 446-458, Jan. 2018.

[7] M. Bonnet-Eymard, M. Boccard, G. Bugnon, F. Sculati-Meillaud, M. Despeisse, and C. Ballif, "Optimized short-circuit current mismatch in multi-junction solar cells," Sol. Energy Mater. Sol. Cells, vol. 117, pp. 120-125, 2013.

[8] R. Asadpour, R. V. K. Chavali, M. Ryyan Khan, and M. A. Alam, "Bifacial Si heterojunction-perovskite organic-inorganic tandem to produce highly efficient $\left(\eta T^{*} \sim\right.$ $33 \%$ ) solar cell," Appl. Phys. Lett., vol. 106, no. 24, p. 243902, Jun. 2015.

[9] H. Chung et al., "Modeling and designing multilayer 2D perovskite / silicon bifacial tandem photovoltaics for high efficiencies and long-term stability," Opt. Express, vol. 25, no. 8, p. A311, Apr. 2017.

[10] A. Onno and Z. C. Holman, "Numerical analysis of bifacial silicon-based tandem devices: Shifts in the optimum top-cell bandgap with varying albedo," 2018 IEEE 7th World Conf. Photovolt. Energy Conversion, WCPEC 2018 - A Jt. Conf. 45th IEEE PVSC, 28th PVSEC 34th EU PVSEC, pp. 229-232, 2018.

[11] L. J. Geerligs, D. Zhang, G. J. M. Janssen, and S. L. Luxembourg, "4-Terminal and 2Terminal Tandem Modules in Bifacial Operation: Model Analysis and Comparison," in 35th European Photovoltaic Solar Energy Conference and Exhibition, 2018, pp. 676-680.

J. Zhao et al., "24\% Silicon Heterojunction Solar Cells on Meyer Burger's on Mass Production Tools and How Wafer Material Impacts Cell Parameters," 2018 IEEE 7th World Conf. Photovolt. Energy Conversion, WCPEC 2018 - A Jt. Conf. 45th IEEE PVSC, 28th PVSEC 34th EU PVSEC, pp. 1514-1519, 2018. 
[13] M. A. Green et al., "Solar cell efficiency tables (Version 53)," Prog. Photovoltaics Res. Appl., vol. 27, no. 1, pp. 3-12, Jan. 2019.

[14] PVLighthouse, "Sunsolve," 2019. [Online]. Available:

https://www.pvlighthouse.com.au/sunsolve. [Accessed: 01-Oct-2019].

[15] P. Loeper et al., "Complex Refractive Index Spectra of $\mathrm{CH} 3 \mathrm{NH} 3 \mathrm{Pbl} 3$ Perovskite Thin Films Determined by Spectroscopic Ellipsometry and Spectrophotometry," J. Phys. Chem. Lett., vol. 6, no. 1, pp. 66-71, 2015.

[16] J. Werner et al., "Complex Refractive Indices of Cesium-Formamidinium-Based Mixed-Halide Perovskites with Optical Band Gaps from 1.5 to $1.8 \mathrm{eV}, "$ ACS Energy Lett., vol. 3, no. 3, pp. 742-747, Mar. 2018.

[17] K. Ghimire, D. Zhao, Y. Yan, and N. J. Podraza, "Optical response of mixed methylammonium lead iodide and formamidinium tin iodide perovskite thin films," AIP Adv., vol. 7, no. 7, p. 075108 , Jul. 2017.

[18] A. M. Baldridge, S. J. Hook, C. I. Grove, and G. Rivera, "The ASTER spectral library version 2.0," Remote Sens. Environ., vol. 113, no. 4, pp. 711-715, Apr. 2009.

[19] J. Haschke, O. Dupré, M. Boccard, and C. Ballif, "Silicon heterojunction solar cells: Recent technological development and practical aspects - from lab to industry," Sol. Energy Mater. Sol. Cells, vol. 187, no. July, pp. 140-153, 2018.

[20] European Commission Joint Research Center, "TMY Generator [WWW Document]. Photovoltaic Geographical Information System." [Online]. Available: https://re.jrc.ec.europa.eu/pvg_tools/en/tool s.html\#TMY. [Accessed: 08-Oct-2019].

[21] C. W. Hansen et al., "Analysis of irradiance models for bifacial PV modules," 2017 IEEE 44th Photovolt. Spec. Conf. PVSC 2017, pp. 1-6, 2017.

[22] R. Perez, P. Ineichen, R. Seals, J. Michalsky, and R. Stewart, "Modeling daylight availability and irradiance components from direct and global irradiance," Sol. Energy, vol. 44, no. 5, pp.
271-289, 1990.

[23] N. Martin and J. M. Ruiz, "Calculation of the PV modules angular losses under field conditions by means of an analytical model," Sol. Energy Mater. Sol. Cells, vol. 70, no. 1, pp. 25-38, Dec. 2001.

[24] C. Gueymard, "Smarts2, A Simple Model of the Atmospheric Radiative Transfer of Sunshine: Algorithms and performance assessment," 1995.

[25] C. A. Gueymard, "Parameterized transmittance model for direct beam and circumsolar spectral irradiance," Sol. Energy, vol. 71, no. 5, pp. 325-346, Nov. 2001.

[26] O. Dupré, R. Vaillon, and M. A. Green, Thermal Behavior of Photovoltaic Devices. Springer International Publishing, 2017.

[27] M. T. Hörantner and H. J. Snaith, "Predicting and optimising the energy yield of perovskite-on-silicon tandem solar cells under real world conditions," Energy

Environ. Sci., vol. 10, no. 9, pp. 1983-1993, 2017.

[28] E. T. Hoke, D. J. Slotcavage, E. R. Dohner, A. R. Bowring, H. I. Karunadasa, and M. D. McGehee, "Reversible photo-induced trap formation in mixed-halide hybrid perovskites for photovoltaics," Chem. Sci., vol. 6, no. 1, pp. 613-617, 2015.

[29] T. C.-J. Yang, P. Fiala, Q. Jeangros, and C. Ballif, "High-Bandgap Perovskite Materials for Multijunction Solar Cells," Joule, vol. 2, no. 8, pp. 1421-1436, Aug. 2018. 